\title{
Insights into New Media Use by International Students: Implications for Cross-Cultural Adaptation Theory*
}

\author{
Blake Hendrickson ${ }^{1 \#, ~ D e v a n ~ R o s e n ² ~}$ \\ ${ }^{1}$ University at Buffalo Undergraduate Degree Program, Singapore Institute of Management (SIM), Singapore \\ ${ }^{2}$ Ithaca College, Roy H. Park School of Communications, New York, Ithaca \\ Email: "blakehen@buffalo.edu, drosen@ithaca.edu
}

How to cite this paper: Hendrickson, B. and Rosen, D. (2017) Insights into New Media Use by International Students: Implications for Cross-Cultural Adaptation Theory. Social Networking, 6, 81-106. https://doi.org/10.4236/sn.2017.62006

Received: January 19, 2017

Accepted: March 3, 2017

Published: March 6, 2017

Copyright @ 2017 by authors and Scientific Research Publishing Inc. This work is licensed under the Creative Commons Attribution International License (CC BY 4.0).

http://creativecommons.org/licenses/by/4.0/

\section{c) (i) Open Access}

\begin{abstract}
The current study uses a longitudinal, mixed-method approach to investigate the role that new media, such as social networking sites and video chat, play in cross-cultural adaptation and international student friendship network development. Results indicate that international students significantly increase and adapt their new media use while abroad to communicate globally with their friends and family, and locally with their newly formed relationships. Furthermore, social networking site host national friends do not necessarily lead to the development of face-to-face host national friends; however, interaction with established face-to-face host national friends and friend groups via new media platforms leads to an increased understanding of host communication patterns. Finally, this study proposes that researchers who apply Kim's [1] cross-cultural adaptation theory consider incorporating Host New Media Communication as a principal concept.
\end{abstract}

\section{Keywords}

New Media, International Students, Argentina, Social Networking Sites, Video Chat

\section{Introduction}

In 1977, Stephen Bochner and colleagues analyzed the friendship networks of international students and distilled the networks into three categories: co-nationals, multi-nationals, and host nationals, theorizing that these friendship types served unique psychological functions for individuals in new cultural environments [2]

${ }^{*}$ Research Conducted at: FLACSO Argentina (Facultad Latinoamericana de Ciencias Sociales) Ayacucho 555 (C1026AAC) Capital Federal, Argentina. 
[3]. Four decades later, due to innovative new media such as social networking sites and video chat, the way in which international students manage these newly developed friendships has evolved. Furthermore, new media facilitates continuous contact with distant family and friends while enabling individuals to stay abreast of the social, cultural, and political life of their home culture [4]. Consequently, individuals can support relationships globally and locally, depending on the manner in which they exploit the new media resources afforded to them [5].

Understanding the impact that new media use has on the interpersonal relationship development of those living in new cultural environments is important for a holistic understanding of adaption [6]. Past research indicates that international student's friendship networks have an influential role in the cross-cultural adaptation process [1] [7]. More specifically, the intercultural relations' literature is littered with studies linking positive outcomes for individuals who establish friendship with those from the host country [8] [9] [10] [11]. However, social networking sites such as Facebook have arguably muddled the concept and definition of friendship [12], making international student friendship network research more conceptually and operationally complex, particularly when analyzed longitudinally. Furthermore, literature from multiple disciplines suggests that online and offline peer networks are not necessarily two separate spaces due to the mutual influence they can have on each other [13]. Indeed, several researchers have examined the interplay between social networking site (SNS) friends and face-to-face $(\mathrm{FtF})^{1}$ friends [14] [15] [16]; although no researchers have specifically focused on the association between SNS host national friends and FtF host national friends in a study abroad context. The current study uses a mixedmethod approach to longitudinally examine this offline-online friendship dichotomy over the course of a semester, as well as overall SNS and video chat usage patterns to better explain new media's role in the cross-cultural adaptation process. It is particularly beneficial to pair the inherent temporality of adaption concepts with longitudinal operationalization since we are attempting to unpack processes, not just a cross-section of a process. Finally, much of the literature examining the effects of international students' new media use is situated in Anglo or European countries. The current study analyzes international students from around the world living in Buenos Aires, Argentina, an ideal country due to its history of receiving foreign students, and the recent international student surge over the last decade [17] [18].

The structure of this article is as follows; the first section presents Kim's [1] cross-cultural adaptation theory, a commonly used and recommended integrative intercultural communication theory [19] [20] [21] [22], discusses potential new media influences, and poses two research questions. The second section presents the longitudinal, mixed-method procedure, gives an overview of the Argentine educational environment, and analyzes the two research questions. The third section offers a discussion outlining the implications of these findings ${ }^{1}$ For this investigation the acronym SNS refers to social networking sites while FtF is short for face-to-face. In most cases they appear as adjectives describing friendship connections online (SNS friends) versus offline ( $\mathrm{FtF}$ friends). 
for cross-cultural adaptation theory and international education, study limitations, and directions for future research.

\subsection{New Media and Cross-Cultural Adaptation}

New media are the new methods and social practices of communication, representation, and expression that have developed using the digital, multimedia networked computer and the way this device has transformed both mass and interpersonal communication mediums [23]. New media is a global term that unifies a multifaceted mix of characteristics; including digital, interactive, hypertextual, virtual, networked, and simulated [23]. The current study uses the term new media as an overarching concept that includes future technological and media change and is not limited to those particular media which are new at the time of writing [23]. Using a broadly defined term such as new media follows Kim's [1] recommendation that in order to better inform the multidimensional reality of the cross-cultural adaptation phenomenon researchers must seek to expand the conceptual domain.

Kim's [1] cross-cultural adaptation theory predicts and explains the dynamic transformation process that individuals undergo when entering new cultural environments. An individual's ability to communicate effectively with locals is central to this process and said ability is best acquired through participation in host social communication, which is the formation of interpersonal relationships with host nationals, and through participation in host mass communication such as watching local television, reading local newspapers, and listening to local radio. These two forms of communication have undergone considerable changes in recent years.

Wimmer and Dominick [24] modified their definition of mass media (i.e. the channels that carry mass communication) to include smart media such as smartphones, smart TVs, and tablets. These media are essentially hand-held computers that make international students' mass communication activities more interactive. Students can produce and share information with the masses while simultaneously consuming traditional host mass communication on the same device [24]. One example of the relationship between traditional mass media and new media comes from a study linking television viewing and increased promiscuity in SNS friending behavior [14]. Further examining the nuanced ways in which new media advances in mass communication consumption and production influence the cross-cultural adaptation process is necessary [20], however not the principal objective of this investigation. The current research focuses on the influence that new media has on international students' interpersonal communication activities with host nationals.

With the presence of new media such as SNS, international students can facilitate interpersonal relationships with host nationals through diverse means [25]. New media not only provide additional forums for interaction, but these interactions are through mediums in which the burgeoning host national friendships are merely a click away, helping to overcome the linguistic and commu- 
nicative barriers that may be present during intercultural communication situations [26]. Along with providing additional mediums for participation in host social communication, new media also enhance communication with distant relationships.

With the introduction of SNS and video chat programs, international students are better able to maintain communication with family, friends, and other previously established support networks [13]. Video chat allows individuals to share activities and spend time together, resulting in stronger feelings of connectedness. With the addition of a variety of nonverbal communicative elements video chat programs represent face-to-face settings that produce intimate, shared living experiences capable of connecting two locations more than other computer mediated technologies [27]. However, whether this continuous and potentially intimate communication with distant relationships facilitates more successful adaptation to new cultural environments is up for debate [28]. Researchers have identified links between sojourner media use oriented toward the home country with poor emotional adjustment [29] and less psychological adaptation [30]. Conversely, Savicki [10] reported no relationship between individuals who reported more online contact with distant relationships and less contact with the host culture. Studies analyzing new media use patterns within the new cultural environment suggest that, although new media use helps students build co-national support networks [31] [32], it works to direct students into co-national groups and discourages integration [33]. Such discouraged integration is problematic considering that participation in interpersonal communication activities with co-nationals restricts one's ability to form friendship with host nationals [1] [9], acquire linguistic and cultural knowledge [34], and affects gains in intercultural learning [35].

Cemilcilar et al. [4] argue that if new media use is used only as a socialization supplement it should positively influence and not hinder the adaptation process. Indeed, current literature strongly implies that the Internet plays a positive role in reestablishing peer networks for those in transition [13]. Various authors suggest that those who take advantage of technology afforded to them are better connected [4] [36] and that SNS such as Facebook can facilitate the maintenance of close friendships and distant relationships [37] [38]. Rui and Wang [26] stress that the effects of SNS use on cross-cultural adaptation are likely dependent on who the international students are communicating with. Consequently, this research considers the potential for new relationship formation embedded in SNS by examining the interplay between SNS and FtF friendship, specifically focusing on host national friends.

\subsection{Social Networking Sites and FtF Friendship}

When International students enter new cultural environments they build new FtF friendships with varying degrees of intimacy (strong/bonding vs. weak/bridging ties) and these distinctions affect the cross-cultural adaptation process in unique ways [39]. Granovetter [40] [41] explored the concept of weak ties to explain how individuals make social advancements by attaining new information and 
getting recruited into new groups. Weak ties with host nationals give international students the opportunity to learn the communication patterns of the host culture [1], help individuals integrate into new cultural environments [42], and having a varied bandwidth of host national friendship is linked to increased feelings of social connectedness [7]. In should be noted that when Granovetter presented the strength of weak ties theory, online social networks were nonexistent. Arguably, an international student has the ability to accumulate new weak tie host national connections through SNS at a much faster rate than in the past; connections that can be sustained by introducing a third, more recent type of social connection, latent ties, which have become more relevant with new media advances. A latent tie can be thought of as a tie for which a link is technically available but that has not yet been initiated by social interaction [43]. An important characteristic of latent ties is that they are not established by individuals, but through organizational structures, such as through internal email lists [43]. Other researchers expand the definition of latent ties using them to describe certain SNS friendships, i.e. individuals who someone met online through a SNS, individuals who someone has a passing awareness of, or individuals who someone has briefly met FtF [44]. Through SNS these latent ties have the potential to be converted into weak ties and/or strong ties [44].

SNS give international students the ability to build relationships with host nationals that begin as latent ties, perhaps by searching on a SNS for individuals that they may have met in person at a social gathering or class, but were unable to strengthen the bond at the time [45]. Furthermore, participation in SNS social functions, such as Facebook groups, arguably provides students access to embedded latent ties. Additionally, Facebook is a media that promotes, facilitates, triggers, and influences new friendship development; however, this element is highly dependent on users' attitudes and perceptions [16]. Given the friendship nature inherent to SNS many scholars have examined the relationship between online and offline friendship patterns.

Research comparing SNS friendship networks and FtF friendship networks shows that, although these networks overlap whereby $\mathrm{FtF}$ friends are typically included among SNS friends, they tend to not mirror each other [14] [15] [46]. In general, SNS friendship networks expand but rarely regress because people usually do not break SNS ties. It is unlikely that individuals have the time and energy to invest in all SNS ties that they maintain [47]. Indeed, one study examining SNS usage found that Facebook use significantly predicted online bridging capital, but did not predict offline bridging capital [48].

There is a strong argument that SNS increase international students' ability to connect to and communicate with host nationals and potentially build relationships through the online interface of SNS. However, it is still not clear if SNS use and the accumulation of more SNS host national friends leads to the development of more FtF host national friends in new cultural environments.

\subsection{Two Research Questions}

In order to explain international students new media use in their new cultural 
environment, analyze the impact that this usage has on FtF host national friendship, and incorporate new media related theorems into cross-cultural adaptation theory the following research questions are posed:

RQ1: How do International students use new media such as SNS and video chat programs to maintain distant relationships and communicate with those in their new cultural environment? How do these patterns change over the course of a semester?

RQ2: What is the relationship between SNS use, SNS host national friendship, and FtF host national friendship? How do these patterns change over the course of a semester?

\section{Method}

The current investigation uses a quantitative survey and longitudinal, prospective panel, technique to assess the same participants on two separate occasions [49]. Scholars analyzing the experiences of individuals crossing cultures emphasize the use of longitudinal research design [9] [22] [26]. By following a given sample of participants throughout a specific time period, researchers can more accurately document patterns in the cross-cultural adaptation process [1]. The current study also incorporates in-depth, qualitative interviews with a sample of the international students who completed the survey. Investigators refer to this specific mixed-method approach as triangulation, a method that produces two data sets and findings that converge on the same proposition [50].

\subsection{Mixed-Method Data Analysis}

The current analytic approach examines the quantitative data using traditional null hypothesis significance testing setting the $p$ value at 0.05 ; however each test reports the actual $p$ values, the effect sizes, and confidence intervals [51]. The qualitative data is analyzed using a classic analytic coding procedure whereby participant answers are organized into variables using an excel spreadsheet [52]. Finally, the results are combined at the interpretive level [53]. For example, the quantitative survey reveals the raw number of host national SNS friends an individual has, whereas in-depth interviews introduce context and demonstrate how the subjects feel about and value those particular relationships. One important element to address when conducting mixed-method, triangulation research is the sampling procedure.

\subsection{Sampling Procedure}

Considering the dichotomously different sampling characteristics inherent to quantitative and qualitative research this investigation employs a sequential mixedmethod procedure [54]. In this case, a QUAL-QUAN-QUAL sequence. First, the researcher used snowball or chain referral sampling [54] [55] to select universities and study abroad programs, arrange qualitative in-depth interviews with respective program directors, and gain access to international students. Due to the important distinctions in international student experiences across study abroad 
learning contexts [35] [56], the sampling goal was to recruit participants studying in a variety of different settings. Second, it incorporated a probability, selfselecting sampling procedure to achieve a representative sample of international students from each university. Third, for student in-depth interviews it used a purposive, systematic sampling procedure that selects only those international students who participated in the quantitative survey.

\subsection{Research Context: Argentina}

Argentina has a history of receiving foreign students. A 1956 UNESCO publication listed Argentina as the fourth ranked country in the world in terms of countries receiving foreign students from abroad. At the time Argentina reported 5000 - 6000 students; the United States 35,000 - 40,000; France 10,000 20,000; and the UK 10,000 - 14,000. According to this study, the number for Argentina is quite accurate, although the exact origin of the students is unclear, although it is likely that the majorities were from other Latin American countries [17]; a trend that continues today with two out of three international students in Argentina being Latin American [18]. UNESCO's 2012 Global Flow of Tertiary students report does not include numbers for students studying in Argentina [57], however in 2011 the Argentine Ministry of Education indicated on their official website that there were more than 50,000 foreign students studying in Argentina [58], a number that had doubled since 2006 [18] [59]. These numbers, albeit unofficial, make Argentina host to the most international students in Latin America.

In 2006, the Argentine Ministry of Education created the Program for the Promotion of the Argentine University (PPUA) with the main goals of promoting Argentine university activities outside of Argentina, increasing the amount of international students in Argentina, and strengthening ties between National universities and local needs [60]. One activity that the PPUA initiated to achieve this goal is to provide funds for Argentine university administrators to represent their respective universities at international education fairs and conferences [59]. The PPUA highlights the quality and affordability of Argentine higher education, the low cost of living and high quality of life in Argentina, varied cultural activities, diverse tourist offering, and opportunities to learn Spanish. Moreover, the PPUA and Argentine Ministry of Education have responded to this wave of other international students by launching a website that provides information regarding educational institutes, housing, cultural activities, immigration procedures, and other pertinent information that students might need upon arrival in Buenos Aires [58]. These features of the Argentine internationalization effort have likely contributed to the expansion of US study abroad programs in Argentina and influx of US students. US student numbers steadily rose from approximately 1200 to 4300 between the years 2000 and 2014, although the US student surge has leveled off in recent years [61].

\subsection{University Breakdown \& Participants}

International students were recruited from 10 different universities or US based 
study abroad centers in Buenos Aires (4 Argentine private universities, 3 public universities, and 3 US based study abroad centers). See Table 1 for international student population and sample by university. From these numbers it can be estimated that approximately 1358 international students received an email from their respective study abroad offices requesting their participation in a research project. The email introduced the nature of the research project, described the two-phase commitment, emphasized that participation was voluntary, and assured that all data would remain confidential. 146 students completed the online survey in Spanish or English two weeks after beginning classes; however several failed to participate again two weeks before classes finished, leaving a sample consisting of 105 international students, 81 (77\%) were female and 24 (23\%) were male. Research shows that a higher ratio of females to male, nearly 2 to 1 , tends to study abroad for a variety of reasons [62]. Participants reported an average age of $22(S D=2.64)$ years at the end of the semester and had completed 5 $(M d n=4$, Mode $=4, S D=2.23)$ semesters of university education at the beginning of the semester, indicating that the majority (87\%) were undergraduate students. Fourteen participants had completed 8 or more semesters upon arrival in Buenos Aires suggesting that approximately $13 \%$ potentially had graduate student status in their respective countries. Students completed the first quantitative survey 4.9 weeks after arriving in Buenos Aires and the second survey 18.6 weeks after arriving, thus a time frame of approximately 13.7 weeks (3.5 months), elapsed between the first and second phases. Three students completed the survey at the beginning and end of their second semester and are not included in the analysis. The participants came from 20 different countries: 46 from Europe (16 Germany, 10 France, 8 Spain, 3 Austria, 2 Finland, 1 from Italy, Netherlands, Norway, Portugal, Czech Republic, Switzerland, Sweden, respecttively); 45 from North America (43 US, 2 Canada); 12 from Latin America (5 Brazil, 3 Colombia, 3 Mexico, 1 Chile); 1 from Morocco, and 1 from India.

Table 1. International student population and sample by university.

\begin{tabular}{ccc}
\hline University & International Student Total & Participants \\
\hline Private University 1 & 300 & 22 \\
Private University 2 & 135 & 12 \\
Private University 3 & 200 & 9 \\
Private University 4 & 190 & 26 \\
Public University 1 & 37 & 2 \\
Public University 2 & 80 & 2 \\
Public University 3 & 200 & 5 \\
Study Abroad Center 1 & 120 & 14 \\
Study Abroad Center 2 & 61 & 6 \\
Study Abroad Center 3 & 35 & 7 \\
Totals & 1358 & 105 \\
\hline
\end{tabular}




\subsection{Instrumentation}

\subsubsection{Friendship Network Grid}

Hendrickson et al.'s [7] friendship network grid assesses an international student's overall FtF friendship network in their new cultural environment. Participants list all their friends, indicate where each friend is from, and indicate relationship strength using given definitions as reference points. One obstacle with using international students from distinct countries is that friendship is defined differently across cultures [9] [63] [64] [65] [66], thus this research presents a potential western bias as the given definitions are based on friendship theorizing in the United States [67]. To be sure, researchers in other national contexts have reported similar characteristics [65].

\subsubsection{New Media Use Questionnaire}

The current study assessed SNS usage with an adapted Facebook intensity scale created to measure university students' SNS usage per day and friendship totals [37]. First, participants indicated if they use a SNS, how many minutes per day they spend on their SNS (capped at 500 minutes to ensure validity) [68], and approximately how many friends they have (for the site that they use most often). Second, participants indicated how many of those friends were co-national, host national, and/or multi-national. Researchers comparing participant reports of Facebook friends and usage intensity with actual friend counts and usage intensity found high correlations for friends $(r=0.96)$ and moderately high correlations for intensity $(r=0.45)$ [68].

Participants indicated if they use a video chat service (e.g. Skype) to keep in contact with individuals not in Buenos Aires. If they answered yes to the first question they subsequently reported approximately how many video calls they make per month and how many different people they call.

\subsubsection{In-Depth Interview Questions}

Researchers conducted in-depth interviews regarding new media use in Spanish and/or English with 34 international students who completed the online survey. Example questions include: How do you use video chat and SNS to communicate with distant relationships? How do you use SNS to communicate with individuals in Buenos Aires? How much time do you spend using SNS and video chat? Who are your SNS friends?

The mean interview length was 1 hour and 13 minutes ( $S D=15$ minutes). Interviewees came from 13 different countries: 14 (41\%) from Europe, 15 (44\%) from North America (14 US, 1 Canada), and 5 (15\%) from Latin America. Thus, in terms of regional origin the 34 students interviewed represent a sample nearly proportionate to the larger sample that completed the online survey (See Appendix for interviewee reference list and demographics).

\section{Results}

The results section contains two parts. The first part employs paired sampled t-tests in analyzing research question one concerning SNS and video chat usage 
patterns and changes over time. The second part employs correlation analysis to examine research question two which explores the relationship between SNS friends and FtF friendship networks. Each quantitative analysis is followed by descriptive in-depth interview findings.

\subsection{New Media Usage Patterns}

Research Question 1 inquired as to how international students use new media such as SNS and video chat programs to maintain distant relationships and communicate with those in their new cultural environment, and how this pattern changes over the course of a semester. All but one international student reported using a SNS. Upon arrival in Buenos Aires, students reported to dedicate an average of $138(S D=130 ; M d n=90)$ minutes per day to a SNS, while at the end of the semester students reported an average of $114(S D=131 ; M d n=75)$ minutes per day. A paired sample t-test revealed that this was not a significant decrease $t(100)=1.42, p=0.16$, CI $[-9,57], d=0.20$, in the amount of time spent using a SNS per day. During in-depth interviews students discussed their SNS use and the role that it plays in their lives in Buenos Aires.

Students did not report their new media use before coming to Buenos Aires on the quantitative survey; however in-depth interview participants emphasized a drastic increase in their new media use upon arrival. Such changes are directly related to an increase in SNS use, specifically Facebook, which tended to play a central role in students' lives both academically and socially. The following is a typical response to the question, "How do you use SNS in your daily life here?"

Here, a lot, haha, the truth is in Prague I didn't use Facebook that much, but here yes, because it's the easiest way to communicate with both my friends in Prague and my friends here (Ref. 16).

Facebook was overwhelmingly the principal means of communication for the majority of international students who participated in this study. Students use the words essential, necessary, key, and important to describe Facebook's role in their daily communication. Along with discussing increased SNS use, students also discussed their different SNS friendship patterns since arriving in Buenos Aires. One student from Switzerland stated:

My Facebook friends have increased a lot, if you look at a statistic of my Facebook friends over the past 2 - 3 years, my friends have, I don't know [subject makes a hand gesture with gradual increase] but in the past 3 months [subject gives a hand gesture with his hand going straight up and laughs] here everyone uses Facebook a lot more (Ref. 10).

The above comment from interview Ref. 10 highlights the notion that new media usage patterns change when international students study abroad, relying on different applications and platforms. Along with discussing their increased Facebook use, students also went into detail as to how they used Facebook for organizing both social and academic events, and in most cases students participate in several different groups. Most study abroad programs have a formal Facebook group to disseminate academic information regarding classes, registra- 
tion, and visa requirements. Students then typically arrange a separate student only group used for sharing social information. A US student explained this distinction:

Facebook is huge here, there are two groups, the whole program, directors, and visiting faculty for normal stuff and then the "kids group" for nightlife, that things always gettin' blown up with events, pictures, comments, whatever, the main way we communicate (...) I spend a whole lot more time on Facebook than ever before (Ref. 25).

Students also organize more intimate groups; a German girl discussed her Facebook group with other German friends at her private university [5], a US girl mentioned that the 14 students from her US university program had a special sub-group [12], and a German girl studying at a public university discussed her two Facebook groups, one is a small group for playing music and cooking dinner and the other is for all the girls on her soccer team. She stated:

I don't know how everybody in Argentina uses Facebook, but the girls from my group write everything, everything, every little detail, and every thought (...) my soccer shoes smell really bad (...) and in Germany people don't share so much information (Ref. 33).

This particular student, Ref. 33, had contact with her teammates twice a week at practice and daily communication online, and the above comment illustrates how students can learn communication behaviors and habits of Argentines through FtF communication as well as online through small group forums, wall posting, and personal messages. Additionally, students learn group friendship dynamics as well as cultural norms regarding appropriateness and humor.

Students also reported using SNS, specifically Facebook, to maintain contact with distant family and friends and in some cases described their use as divided between global and local relationships [7] [11] [25]. In terms of communication with distant family, the majority reported that video chat, particularly Skype, was the principal new media platform they used.

At the beginning of the semester $93 \%$ of students reported using video chat, they made an average of $21(S D=22 ; M d n=13)$ video calls per month to an average of $6.7(S D=4 ; M d n=5)$ different people. At the end of the semester $91 \%$ of students reported using video chat, they made an average of 17 ( $S D=20 ; M d n$ $=10)$ video calls per month to an average of $5.5(S D=3 ; M d n=5)$ different people. Pair sampled t-tests showed this to be a significant decrease in the amount of video chat calls per month at the end of the semester $t(98)=2.34, p=$ 0.02 , CI $[0.73,8.8], d=0.24$. Furthermore, the amount of different people that students called $t(98)=2.80, p=0.01$, CI $[0.34,2.0], d=0.28$ also decreased significantly.

Correlation coefficients were run to further explore potential relationships between this significant decrease in video chat usage and FtF host national friendship. There were no significant relationships between video chat variables and $\mathrm{FtF}$ host national friends upon arrival or departure; however there was a significant correlation $r(98)=-0.21, p=0.04$ between FtF host national friend- 
ship change and video chat change. A finding suggesting a relationship between increases in FtF host national friendship and decreases in video chat calls per month.

During interviews students discussed the importance of video chat, particularly Skype, for maintaining relationships with their family, friends, and partners. A Columbian student described his video chat usage:

Before coming to Buenos Aires I gave the basic Skype course to my parents, my mom adores Skype, 10, maybe 5 years ago, she would have had to wait 6 months to see me, now she can see me every day, every night, it's super important. I also use Skype with my girlfriend. Skype is for communicating with Colombia (Ref. 3).

The majority of students stated that they used video chat, specifically Skype, to communicate with and maintain relationships with their distant family and friends. One US student described the relationship maintenance function of video chat:

I Skype my family twice a week and my best friend once a week (...) and actually being abroad with slight communication has strengthened the relationships with all the people I have back home (Ref. 26).

Some students reported using Skype almost every day [24], others two to three times a week [30] [33], and others use it, but less often [10]. Skype and Facebook were the unanimous choice for students in communicating with distant relationships.

\subsection{SNS Use, SNS Host National Friendship, and FtF Friendship}

Research Question 2 inquired as to the relationship between SNS usage, SNS host national friendship, and FtF host national friendship and subsequent changes over time. First, Pearson's correlations coefficients showed no significant relationships between time spent on SNS and FtF host national friendship at the beginning $r(100)=-0.01, p=0.96$, nor at the end of the semester $r(101)=$ $-0.01, p=0.90$. A friendship change variable was created for the analysis, which represented the friendship difference between phase 1 and phase 2 (Table 2 shows these changes). There was a significant negative correlation between SNS usage at the end of the semester and increases in FtF host national friends $r(100)$ $=-0.21, p=0.04$, suggesting a relationship between students who spent less time on SNS at the end of the semester and increases in FtF host national friendships over time.

Second, Pearson's correlation coefficients showed no significant relationship between SNS host national friends and FtF host national friends at the beginning $r(100)=0.01, p=0.93$, nor at the end of the semester $r(101)=-0.07, p=0.50$. See Table 3 for all correlations at the beginning of the semester and Table 4 for all correlations at the end of the semester. Additionally, Pearson's correlation coefficients showed no significant relationship between SNS host national friends at the beginning of the semester and host national $\mathrm{FtF}$ increases over time $r(100)=-0.12, p=0.23$; nor with SNS host national friends at the end of 
Table 2. SNS and FtF friends at the beginning and end of the semester.

\begin{tabular}{ccc}
\hline SNS Friends & Arrival M $(S D)$ & Departure M $(S D)$ \\
\hline Total & $505(249)$ & $524(261)$ \\
Co-National & $378(232)$ & $375(236)$ \\
Multi National & $23(83)$ & $26(24)$ \\
Host National & $109(106)$ & $114(112)$ \\
FtF friends & Arrival M $(S D)$ & Departure $\mathrm{M}(S D)$ \\
Total & $17.75(10.6)$ & $20.86^{*}(12.35)$ \\
Co-National & $7.8(6.0)$ & $7.6(6.24)$ \\
Multi National & $5.66(5.43)$ & $7.41^{\star}(7.74)$ \\
Host National & $4.29(4.99)$ & $5.83^{\star}(6.09)$ \\
\hline
\end{tabular}

Note: ${ }^{*}$ denotes Pair-sampled t-test significant differences for changes between arrival and departure ${ }^{\star} p<$ 0.01 , two-tailed. Totals are approximations reported by students, not summations of three friendship groups.

Table 3. Correlations between SNS friends and FtF friends at the beginning of the semester.

\begin{tabular}{lccccc}
\hline \multicolumn{1}{c}{ Network Variables } & 1 & 2 & 3 & 4 & 5 \\
\hline 1. SNS Host & - & & & & \\
2. SNS Co. & 0.01 & & & & \\
3. SNS Multi & -0.01 & -0.16 & & & \\
4. FtF Host & 0.01 & 0.02 & -0.01 & & \\
5. FtF Co. & $-0.35^{*}$ & 0.20 & 0.12 & 0.09 & \\
6. FtF Multi & 0.21 & -0.20 & -0.05 & $0.38^{*}$ & -0.11 \\
\hline
\end{tabular}

Note: ${ }^{*} p<0.006$, two tailed.

Table 4. Correlations between SNS friends and FtF friends at the end of the semester.

\begin{tabular}{lccccc}
\hline \multicolumn{1}{c}{ Network Variables } & 1 & 2 & 3 & 4 & 5 \\
\hline 1. SNS Host & - & & & & \\
2. SNS Co. & -0.01 & & & & \\
3. SNS Multi. & $0.31^{*}$ & -0.02 & & & \\
4. Ftf Host & -0.07 & -0.13 & $0.36^{*}$ & & \\
5. Ftf Co. & $-0.31^{*}$ & 0.20 & -0.21 & 0.03 & \\
6. Ftf Multi. & $0.31^{*}$ & -0.22 & 0.07 & 0.23 & -0.06 \\
\hline
\end{tabular}

Note: ${ }^{*} p<0.006$, two tailed.

the semester and host national FtF increases over time $r(100)=-0.16, p=0.12$. There was also no relationship between SNS and Ftf host national friendship change $r(100)=-0.07, p=0.50$.

Third, in order fully explore students' overall friendship networks; several simultaneous tests examined the relationship between reported SNS multi-national, co-national, and host national friends and FtF multi-national, co-national, 
and host national friends. To account for experiment-wise error a Bonferroni correction was used to reduce the risk of Type 1 error. Nine tests were run using an alpha level of 0.006. Pearson's correlations coefficients revealed a significant negative relationship between SNS host national friends and FtF co-national friends at the beginning of the semester $r(100)=-0.35, p=0.000$ and also at the end of the semester $r(101)=-0.31, p=0.002$. Additionally, there was a positive relationship with SNS host national friendship and FtF multi-national friendship at the end of the semester $r(101)=0.31, p=0.001$. Finally, there was a positive relationship between SNS multi-national friends and FtF host national friends at the end of the semester $r(101)=0.36, p=0.001$.

These correlations suggest three relationship patterns between SNS and FtF friendship networks. First, students with more FtF co-national friends in Buenos Aires tended to have significantly less SNS host national/Argentine friends at the beginning and end of the semester. Second, students who reported more FtF multi-national friends in Buenos Aires reported more SNS host national/Argentine friends at the end of the semester. Third, students with more FtF host national/Argentine friends in Buenos Aires reported more multi-national SNS friends at the end of the semester.

To further explore and explain these correlations the students were split into two groups according to university context; students at Argentine universities and students at US based study abroad centers. An independent samples t-test showed that at the beginning of the semester students studying at Argentine universities had significantly more SNS host national friends $(M=127, S D=111)$ than students at US based study abroad centers $(M=57, S D=70), t(70)=3.71, p=0.001$, CI $[32,107], d=0.69$. At the end of the semester students studying at Argentine universities also had significantly more SNS host national friends $(M=129, S D=$ 116) than students at US based study abroad centers $(M=70, S D=90), t(55)=$ $2.68, p=0.01$, CI $[15,104], d=0.55$. Thus, students studying in a university context with Argentine students reported significantly more SNS Argentine friends than students studying in a university context with no Argentines.

During in-depth interviews students compared their SNS friendship networks to their FtF networks. A German girl discussed the difference between her FtF Argentine friends and SNS host national friends:

I think I have like 50 more new friends. It's an interesting phenomenon; in Facebook I have a lot of Argentine friends but in reality, no. When I get back to Germany Ill have to delete people from the list because they' re not....friends (Ref. 5).

Not all students reported this friendship pattern, another German girl at the same private university said that the Argentine friends that she had on Facebook were the same as her face-to-face Argentine friends (Ref. 2). Indeed, not everybody uses Facebook the same way, nor has the same friending patterns [14] [69].

\section{Discussion}

Findings in regards to new media use among international students generally 
support parallel findings in existing literature [25] showing that new media play a persistent role not only in international students' communication with their families and friends back home, but also in their daily communication with those in Buenos Aires. However, by longitudinally examining the new media use of a diverse sample of international students in Argentina, a relatively unexplored research context, findings can be generalized with more confidence, while also extending into discussions of adaption processes. The current investigation demonstrates that students not only increase their new media use while abroad, but also modify and adapt their use to the new cultural environment. Furthermore, the longitudinal design highlights the changes that new media and SNS friendship patterns might undergo over the course of a semester. In general, video chat usage significantly decreases and SNS decreases slightly, although not statistically significant, over the course of the semester, while SNS host national friends increase rapidly upon arrival and subsequently change little over time. By separating SNS friendship and FtF friendship into co-national, host national and multi-national groups this study concentrates on who students communicate with online while examining possible connections. Findings did not show a significant relationship between SNS host national friends and FtF host national friends, however correlation and university context analyses revealed several significant patterns between other SNS and FtF friendship variables. Overall, results strongly support incorporating new media use as a central communicative aspect in future theoretical development of cross-cultural adaptation processes.

\subsection{SNS Friendship vs. FtF Friendship}

Data from this study indicate complex interactions between SNS and FtF friendships. First, there was no relationship between FtF host national friendship and SNS host national friendship. One major limitation of this study's design is that these data do not distinguish between SNS friends that students had before arriving in Buenos Aires and the friends that they added after arriving. However, given the average age (22 years) of the sample and semesters of post-secondary education completed (5 semesters) it is possible, albeit speculative, that participants added a high amount of their SNS host national friends after arriving in Buenos Aires. However, it is not reasonable to make this assumption for co-national and/or multi-national SNS friends. The number of SNS host national friends in the first 4.7 weeks was relatively large (109) however this number remained rather constant 3.7 months later when students reported (114). At the beginning of the semester international students reported an average of $4.29 \mathrm{FtF}$ host national friends with the instructions of including both their strong and weak ties. The discrepancy in total SNS host national friends and FtF weak and strong tie host national friends could be attributed to the existence of many latent ties, ties that could technically be mobilized at any time. Ellison et al. [44] argue that Facebook gives users the ability to convert latent ties into weak ties; however data from this research do not suggest the conversion of latent SNS host national ties to FtF host national weak ties, an insight generated from the 
longitudinal analysis herein. International students may very well have numerous SNS host national friends, but this does not mean that they have more FtF host national friends or that SNS host national friends led to them developing more FtF host national friends.

Results did indicate several relationships between SNS friendships and FtF friendships when including co-national and multi-national variables in the analysis, suggesting that there is not a complete disconnect between online and offline friendship patterns. Students with more FtF co-national friends had fewer SNS host national friends, students with more FtF multi-national friends had more SNS host national friends, and students with more FtF host national friends had more SNS multi-national friends. Furthermore, when examining the university context students at Argentine universities reported significantly more SNS Argentine friends than students at US based study abroad centers. Facebook is generally considered a social network maintenance site where individuals maintain contacts initially made in face-to-face contexts [14]. Individuals with more FtF co-national friends will likely report less contact with host nationals [1] and consequently have fewer SNS host national friends. Using this line of reasoning it makes sense that those who have more FtF friendships and contact with more others (host national or other countries), will display this tendency online. Taken as a whole, our data suggest that SNS friends tend to be reflections of FtF friendship groups and not catalyst leading to new friendships.

\subsection{New Media Use Patterns}

By examining SNS and video chat usage longitudinally, this investigation provides insight into the effect of computer-mediated communication on distant relationships, and contributes to the discussion as to whether new media use detracts students from developing FtF host national relationships. Through SNS and video chat, students successfully maintained and in some cases enhanced distant relationships, a finding consistent with studies targeting other mediums. For example, researchers found that mediated communication through telephone and the Internet neither improved nor detracted relational satisfaction and closeness [70]. Haythornthwaite [43] categorizes online exchanges as being as real as offline exchanges in terms of their impact on the tie and argues that it does not matter if the tie is maintained face-to-face or online, the relationship is what is important. McLuhan and McLuhan's Laws of Media theory [71] is particularly relevant here. SNS and video chat are mediums that enhance, intensify, and amplify human ability to maintain existing relationships. Although, individuals have limits as to the number of relationships that they can maintain [47], and longitudinal analysis of video chat and SNS use in this study highlights this. First, at the end of the semester students who spent less time on SNS reported an increase in FtF host national friends. Second, over the course of the semester, international students significantly reduced the number of people they called and number of video chat calls they made per month, and this latter decrease was correlated with increases in FtF host national friendship. The longitudinal 
nature of this finding implies that as international students developed new FtF host national friends in Buenos Aires they were either unable to maintain as many previous ties through video chat, or relied less on them for support. Thus, longitudinal analysis suggests that when international students arrive in a new cultural environment they both modify the specific new media platforms they use and intensify overall new media use, potentially reflecting initial transitional stress [13]. Over the course of the semester their new media use decreases, and this decrease is most likely with their global communication, a finding corroborating previous research [30].

One important finding that arose during in-depth interviews was the prominence of Facebook groups for international student organization and communication. Such behaviors indicate the potential utility of studying affiliation networks in better understanding the cross-cultural adaptation of international students. Membership in online collectives or groups brings individuals together at social events, thus providing conditions for development of interpersonal connections [72] [73]. Analyzing an individual's group affiliation may be as useful as analyzing their ego-network, international students who are affiliated with groups laden with host national/Argentines can potentially develop relationships at FtF social events. Future research dedicated to understanding group affiliation and online communication patterns is necessary.

\subsection{Host New Media Communication \& Cross-Cultural Adaptation Theory}

Although findings from this study do not indicate a direct relationship between SNS host national friends and FtF host national friends, they do not disregard the value of having SNS host national friends and participation in online communication with host nationals. Such activities may not inherently manifest in FtF friendship, however they do help students learn host national online communication patterns and behaviors. Research studies indicate that cultural differences exist in how individuals communicate online [74], specifically self-disclosure [75] [76]. Yildiz [77] suggests that due to language anxiety Chinese international students in the UK tended to self-disclose more in online contexts than in face-to-face situations. Indeed, a German international student [33] commented on the difference between what her German counterparts disclose on Facebook and what her Argentine friends share with the Facebook group.

Kim's [1] cross-cultural adaptation theory posits that an increase in both interpersonal and mass communication activities with host nationals will lead to host communication competence. By using new media to communicate with host nationals, individuals gain access to resources and new cultural information which may help them integrate and "to connect with the culture at large" (p. 301) [25]. We propose that a new communicative element, Host New Media Communication, should be included in future theoretical frameworks focused on international student communication. This communication activity fuses the host social communication and host mass communication constructs described 
by Kim [1] and provides strangers with an additional medium for learning the communication patterns of the host culture. On one hand, new media generally mediate host interpersonal communication, i.e. direct, personal SNS messages. On the other hand, new media function as mass communication, i.e. SNS group posts offering invitations to local gatherings, sharing cultural events, and/or advertising products and ideas. In both cases international students have the opportunity to not only observe the online communication patterns of host nationals but also acquire new vocabulary and gain access to novel resources. Through new media interaction with host nationals, international students begin to understand and put host national communication behavior into context, eventually acquiring host communication competence.

Kim [1] poses 21 theorems to explain the rate of cross-cultural adaptation across individuals and environments. The current research proposes that the following theorem be included in her theory: The greater the host new media communication with host nationals, the greater the host communication competence. This hypothesis is tentative; however, findings from the current investigation combined with previous research [25] [26] [48] [78] suggest that it would indeed be supported. Past research has emphasized the role that new media use has in providing international students social support [13] [28], connecting them to those with different cultural backgrounds [26], and providing access to host cultural information and resources [25]. The current study makes an important contribution to scholarly understanding of cross-cultural adaptation by specifically introducing longitudinal analysis to the "who a student communicates with" online [26], while addressing Shuter's [20] call to reconfigure existing intercultural communication theories and include new media influences.

\subsection{Implications for International Education Policy}

There are two important international student well-being issues stemming from our research that international education professionals could consider when designing study abroad programming. First, in some cases study abroad programs create closed Facebook groups that only include co-national students from the program. Considering the function of new media for informational support seeking [25] and findings from the current study highlighting the central role that SNS groups played in international student social organization, it seems reasonable to encourage study abroad programs and international offices to recruit host nationals, include them in online groups, and urge them to participate. Efforts to include host nationals in SNS groups may be particularly important for international students separated from host national students [79]. Institutionalized peer tutoring is one way that universities facilitate contact between international students and host nationals [80] and help make the transition process more positive [81]. To optimize the success of tutor programs, Campbell [81] recommends a combination of large group, small group, and one-on-one activities. Findings from the current study suggest that interactions mediated by new media platforms would complement these offline activities and tutor programs in 
an important way.

Second, programs should make an effort to inform students during pre-departure training of the principal new media platforms commonly used in the new cultural environment. This would give students the opportunity to familiarize themselves with the most common cell phone apps, websites, and SNS used by host nationals.

\subsection{Limitations \& Directions for Future Research}

The first important limitation in this study is that data does not indicate how relationships may have changed between the first day in Buenos Aires and the first time international students completed the online survey, approximately 4.7 weeks later. It is possible that international students form their friendships fast, often within the first few days, and findings from this study do not indicate what influence SNS had during that time period. Research focused on how SNS function for relationship initiation within the first days or weeks is unfortunately beyond the scope of this study, but would have only been possible if the subjects had been solicited prior to their arrival; a limitation that also elicits a recommendation for future research in this area.

The second important limitation is that students only reported information for the SNS that they used most often. During in-depth interviews, Facebook was unanimously the site that students used most often. However, SNS sites with other formats could potentially play a role in the friendship formation process. For example, Couchsurfing is a social networking site for travelers in which participants meet online for the purpose of facilitating offline interaction [73], whereas Facebook is generally used to maintain already established FtF relationships. One of the students interviewed for this study [10] reported that his Couchsurfing host converted into his best host national friend in Buenos Aires. Thus, Couchsurfing directly influenced his FtF friendship network, although he reported to use Facebook approximately 50 minutes a day and answered the quantitative survey with Facebook in mind. It is likely that latent ties function distinctly for Couchsurfing members and for users of other SNS sites.

Future research is necessary to better understand latent ties in distinct online contexts and with other new media technologies. For example, the group and individual messaging functions of WhatsApp messenger provide nuanced ways for participants to be together. Friendships can be made, maintained, and solidified through the sharing of meaningless discussion, jokes, pictures, and videos [82]. International students who join already established WhatsApp friendship groups become exposed to unique friendship dynamics, cultural values, and humor. The intimacy created by WhatsApp coupled with its widespread use worldwide [83] makes it an interesting new media platform for intercultural researchers to examine.

Finally, the current research framework used host national FtF friendship as the main cross-cultural adaptation outcome variable, focusing on the way new media potentially facilitates interpersonal communication. Future research using 
new media variables should continue to explore the relationship with other outcome variables such as language acquisition and participation in host mass communication. For example, analyzing how international students use new media such as YouTube, Netflix, online newspapers, and Spotify to access host mass communication and cultural information would inform scholarly understanding of the evolving cross-cultural adaptation process.

\section{Conclusion}

The research reported above looked to document international student new media use over time, examine the relationship between SNS use and friendship patterns with host national FtF friendship networks, and incorporate new media use into Kim's [1] cross-cultural adaptation theory. Findings illustrate the pervasiveness of increased new media use in the lives of international students both for communicating with distant family and friends and with those in the new cultural environment. Online interaction with host nationals represents an avenue for international students to better understand their communication behavior and subsequently communicate more effectively during intercultural interactions.

\section{References}

[1] Kim, Y.Y. (2001) Becoming Intercultural: An Integrative Theory of Communication and Cross-Cultural Adaptation. Sage, Thousand Oaks.

[2] Bochner, S., McLeod, B.M. and Lin, A. (1977) Friendship Patterns of Overseas Students: A Functional Model. International Journal of Psychology, 12, 277-294. https://doi.org/10.1080/00207597708247396

[3] Bochner, S., Hutnik, N. and Furnham, A. (1985) The Friendship Patterns of Overseas and Host Students in an Oxford Student Residence. The Journal of Social Psychology, 125, 689-694. https://doi.org/10.1080/00224545.1985.9713540

[4] Cemalcilar, Z., Falbo, T. and Stapleton, L.M. (2005) Cyber Communication: A New Opportunity for International Student's Adaptation? International Journal of Intercultural Relations, 29, 91-110. https://doi.org/10.1016/j.ijintrel.2005.04.002

[5] Hampton, K.N., Lee, C.J. and Her, E.J. (2011) How New Media Affords Network Diversity: Directed and Mediated Access to Social Capital through Participation in Local Settings. New Media \& Society, 13, 1031-1049. https://doi.org/10.1177/1461444810390342

[6] Croucher, S.M. (2011) Social Networking and Cultural Adaptation: A Theoretical Model. Journal of International and Intercultural Communication, 4, 259-264. https://doi.org/10.1080/17513057.2011.598046

[7] Hendrickson, B., Rosen D. and Aune, R.K. (2011) An Analysis of Friendship Networks, Social Connectedness, Homesickness, and Satisfaction Levels of International Students. International Journal of Intercultural Relations, 35, 281-295. https://doi.org/10.1016/j.ijintrel.2010.08.001

[8] Bennett, R.J., Volet, S.E. and Fozdar, F.E. (2013) I'd Say It's Kind of Unique in a Way": The Development of an Intercultural Student Relationship. Journal of Studies in International Education, 17, 533-553. https://doi.org/10.1177/1028315312474937 
[9] Church, A. (1982) Sojourner Adjustment. Psychological Bulletin, 91, 540-572. https://doi.org/10.1037/0033-2909.91.3.540

[10] Savicki, V. (2010) An Analysis of the Contact Types of Study Abroad Students: The Peer Cohort, the Host Culture and the Electronic Presence of the Home Culture in Relation to Readiness and Outcomes. Frontiers. The Interdisciplinary Journal of Study abroad, 19, 61-86.

[11] Yusoff, Y.M. (2012) Self-Efficacy, Perceived Social Support, and Psychological Adjustments of International Undergraduate Students in a Public Higher Education Institution in Malaysia. Journal of Studies in International Education, 16, 353-371. https://doi.org/10.1177/1028315311408914

[12] Deresiewicz, W. (2011) Faux Friendship. In: Vie, S., Ed., (E) Dentity, Fountainhead Press, Southlake, 47-50.

[13] Mikal, J.P., Rice, R.E., Abeyta, A. and DeVilbiss, J. (2013) Transition, Stress, and Computer-Mediated Social Support. Computers in Human Behavior, 29, A40-A53. https://doi.org/10.1016/j.chb.2012.12.012

[14] Stefanone, M., Lackaff, D. and Rosen, D. (2008) We're All Stars Now: Reality Television, Web 2.0, and Mediated Identities. Proceedings of the Nineteenth ACM Conference on Hypertext and Hypermedia, Pittsburgh, 19-21 June 2008, 107-112. https://doi.org/10.1145/1379092.1379114

[15] Subrahmanyam, K., Reich, S.M., Waechter, N. and Espinoza, G. (2008) Online and Offline Social Networks: Use of Social Networking Sites by Emerging Adults. Journal of Applied Development Psychology, 29, 420-433. https://doi.org/10.1016/j.appdev.2008.07.003

[16] Tu, B.M., Wu, H.C., Hsieh, C. and Chen, P.H. (2011) Establishing New FriendshipsFrom Face-to-Face to Facebook: A Case Study of College Students. Proceedings of the 44th Hawaii International Conference on System Sciences, Kauai, 4-7 January 2011, 1-10.

[17] Elliot, A.J.A. (1956) The Statistics of Study Abroad. In Part I. Cross-Cultural Education and Education Travel. UNESCO International Social Science Bulletin, 8, 577 750.

[18] Smink, V. (2013) Argentina, a Magnet for University Students. BBC Mundo. http://www.bbc.com/mundo/noticias/2013/05/130524_argentina_estudiantes_extra njeros_vs

[19] Pitts, M.J. (2009) Identity and the Role of Expectations, Stress, and Talk in ShortTerm Student Sojourner Adjustment: An Application of the Integrative Theory of Communication and Cross-Cultural Adaptation. International Journal of Intercultural Relations, 33, 450-462. https://doi.org/10.1016/j.ijintrel.2009.07.002

[20] Shuter, R. (2012) Intercultural New Media Studies: The Next Frontier in Intercultural Communication. Journal of Intercultural Communication Research, 41, 219 237. https://doi.org/10.1080/17475759.2012.728761

[21] Tian, M. and Lowe, J.A. (2013) Intercultural Identity and Intercultural Experiences of American Students in China. Journal of Studies in International Education, 20, 1 17.

[22] Zhang, J. and Goodson, P. (2011) Predictors of International Students' Psychosocial Adjustment to Life in the United States: A Systematic Review. International Journal of Intercultural Relations, 35, 139-162. https://doi.org/10.1016/j.ijintrel.2010.11.011

[23] Lister, M., Dovey, J., Giddings, S., Grant, I. and Kelly, K. (2008) New Media: A Critical Introduction. 2nd Edition, Routledge, New York.

[24] Wimmer, R.D. and Dominick, J.R. (2014) Mass Media Research: An Introduction. 10th Edition, Wadsworth, Cengage Learning, Boston. 
[25] Mikal, J.P. and Grace, K. (2012) Against Abstinence-Only Education Abroad: Viewing Internet Use during Study Abroad as a Possible Experience Enhancement. Journal of Studies in International Education, 16, 287-306. https://doi.org/10.1177/1028315311423108

[26] Rui, J.R. and Wang, H. (2015) Social Network Sites and International Students' Cross-Cultural Adaptation. Computers in Human Behavior, 49, 400-411. https://doi.org/10.1016/j.chb.2015.03.041

[27] Neustaedter, C. and Greenberg, S. (2011) Intimacy in Long-Distance Relationships over Video Chat. Proceedings of the SIGCHI Conference on Human Factors in Computing Systems, Vancouver, 7-12 May 2011, 753-762.

[28] Mikal, J.P. (2011) When Social Support Fits into Your Luggage: Online Support Seeking and Its Effects on the Traditionally Study Abroad Experience. Frontiers. The Interdisciplinary Journal of Study Abroad, 21, 17-40.

[29] Lee, E.J., Lee, L. and Jang, J. (2011) Internet for the Internationals: Effects of Internet Use Motivations on International Students' College Adjustment. Cyberpsychology, Behavior, and Social Networking, 14, 433-437. https://doi.org/10.1089/cyber.2010.0406

[30] Chen, W. (2010) Internet-Usage Patterns of Immigrants in the Process of Intercultural Adaptation. Cyberpsychology, Behavior, and Social Networking, 13, 387-399. https://doi.org/10.1089/cyber.2009.0249

[31] Cao, L. and Zhang, T. (2012) Social Networking Sites and Educational Adaptation in Higher Education: A Case Study of Chinese International Students in New Zealand. The Scientific World Journal, 2012, Article ID: 289356. https://doi.org/10.1100/2012/289356

[32] Ye, J. (2006) Traditional and Online Support Networks in the Cross-Cultural Adaptation of Chinese International Students in the United States. Journal of Computer-Mediated Communication, 11, 863-876. https://doi.org/10.1111/j.1083-6101.2006.00039.x

[33] Mikal, J.P., Yang, J. and Lewis, A. (2015) Surfing USA: How Internet Use Prior to and during Study Abroad Affects Chinese Students' Stress, Integration, and Cultural Learning while in the United States. Journal of Studies in International Education, 19, 203-224. https://doi.org/10.1177/1028315314536990

[34] Brown, L. (2009) An Ethnographic Study of Friendship Patterns of International Students in England: An Attempt to Recreate Home through Conational Interaction. International Journal of Educational Research, 48, 184-193. https://doi.org/10.1016/j.ijer.2009.07.003

[35] Vande Berg, M., Connor-Linton, J. and Paige, M.P. (2009) The Georgetown Consortium Project: Interventions for Student Learning Abroad. Frontiers. The Interdisciplinary Journal of Study Abroad, 18, 1-75.

[36] Kim, Y.Y. and McKay-Semmler, K. (2013) Social Engagement and Cross-Cultural Adaptation: An Examination of Direct and Mediated Interpersonal Communication Activities of Educated Non-Natives in the United States. International Journal of Intercultural Relations, 37, 99-112. https://doi.org/10.1016/j.ijintrel.2012.04.015

[37] Ellison, N.B., Steinfield, C. and Lampe, C. (2007) Benefits of Facebook "Friends:" Social Capital and College Students' Use of Online Social Network Sites. Journal of Computer-Mediated Communication, 12, 1143-1168. https://doi.org/10.1111/j.1083-6101.2007.00367.x

[38] Steinfield, C., Ellison, N.B. and Lampe, C. (2008) Social Capital, Self-Esteem, and Use of Online Social Network Sites: A Longitudinal Analysis. Journal of Applied Developmental Psychology, 29, 434-445. 
https://doi.org/10.1016/j.appdev.2008.07.002

[39] Neri, F. and Ville, S. (2008) Social Capital Renewal and the Academic Performance of International Students in Australia. The Journal of Socio-Economics, 37, 15151538. https://doi.org/10.1016/j.socec.2007.03.010

[40] Granovetter, M. (1973) The Strength of Weak Ties. American Journal of Sociology, 78, 1360-1380. https://doi.org/10.1086/225469

[41] Granovetter, M. (1983) The Strength of Weak Ties: A Network Theory Revisited. Sociological Theory, 1, 201-233. https://doi.org/10.2307/202051

[42] Hyvönen, H. (2008) The Strength of Native Ties: Social Networks of Finnish Immigrants in Estonia. Trames, 12, 421-440. https://doi.org/10.3176/tr.2008.4.04

[43] Haythornthwaite, C. (2002) Strong, Weak, and Latent Ties and the Impact of New Media. The Information Society, 18, 385-401. https://doi.org/10.1080/01972240290108195

[44] Ellison, N.B., Steinfield, C. and Lampe, C. (2011) Connection Strategies: Social Capital Implications of Facebook-Enabled Communication Practices. New Media \& Society, 13, 873-892. https://doi.org/10.1177/1461444810385389

[45] Lampe, C., Ellison, N. and Steinfield, C. (2006) A Face(book) in the Crowd: Social Searching vs. Social Browsing. Proceedings of the 200620 th Anniversary Conference on Computer Supported Cooperative Work, Banff, 4-8 November 2006, 167170. https://doi.org/10.1145/1180875.1180901

[46] West, A., Lewis, J. and Currie, P. (2009) Students' Facebook "Friends": Public and Private Spheres. Journal of Youth Studies, 12, 615-627. https://doi.org/10.1080/13676260902960752

[47] Stefanone, M.A., Kwon, K. and Lackaff, D. (2011) The Value of Online Friends: Networked Resources via Social Network Sites. First Monday: Peer Reviewed Journal on the Internet, 16, 2.

http://firstmonday.org/htbin/cgiwrap/bin/ojs/index.php/fm/article/view/3314/2763

[48] Lin, J.H., Peng, W., Kim, M., Kim, S.Y. and LaRose, R. (2011) Social Networking and Adjustments among International Students. New Media \& Society, 14, 421-440. https://doi.org/10.1177/1461444811418627

[49] Menard, S. (2002) Longitudinal Research Series. Quantitative Applications in the Social Sciences, 2nd Edition, Vol. 67, Sage, Thousand Oaks. https://doi.org/10.4135/9781412984867

[50] Jick, T.D. (1979) Mixing Qualitative and Quantitative Methods: Triangulation in Action. Administrative Science Quarterly, 24, 602-611. https://doi.org/10.2307/2392366

[51] Field, A. (2013) Discovering Statistics Using SPSS: And Sex, Drugs and Rock "N" Roll. 4th Edition, Sage, Thousand Oaks.

[52] Miles, M. and Huberman, M. (1994) Qualitative Data Analysis. An Expanded Sourcebook, Sage, Thousand Oaks.

[53] Sandelowski, M. (2000) Focus on Research Methods: Combining Qualitative and Quantitative Sampling, Data Collection, and Analysis Techniques in Mixed-Method Studies. Research in Nursing \& Health, 23, 246-255.

https://doi.org/10.1002/1098-240X(200006)23:3<246::AID-NUR9>3.0.CO;2-H

[54] Teddlie, C. and Yu, F. (2007) Mixed Methods Sampling: A Typology with Examples. Journal of Mixed Methods Research, 1, 77-100. https://doi.org/10.1177/2345678906292430

[55] Biernacki, P. and Waldorf, D. (1981) Snowball Sampling: Problems and Techniques of Chain Referral Sampling. Sociological Methods \& Research, 10, 141-163. 
[56] Norris, E.M. and Dwyer, M. (2005) Testing Assumptions: The Impact of Two Study Abroad Program Models. Frontiers. The Interdisciplinary Journal of Study abroad, 11, 121-142.

[57] UNESCO Institute for Statistics (2014) Global Flow of Tertiary-Level Students. Argentina. http://www.uis.unesco.org/EDUCATION/Pages/international-student-flow-viz.asp x

[58] Ministerio de Educación de Argentina (MEA) (2011) Estudiar en Argentina. Study in Argentina. http://estudiarenargentina.siu.edu.ar/

[59] Giavi, P.V., Iglesia, G. and Iglesia, J. (2008) Estudiantes internacionales: Una oportunidad para la Argentina. Gobierno de la Ciudad de Buenos Aires Ministerio de Desarrollo Economico. EduArgentina.

[60] Ministerio de Educación de Argentina (MEA) (2010) Promoción de la Universidad Argentina. http://portales.educacion.gov.ar/spu/promocion-de-la-universidad-argentina/

[61] Institute of International Education (IIE) (2016) Host Regions and Destinations of U.S. Study Abroad Students, 2013/14-2014/15. Open Doors Report on International Educational Exchange. http://www.iie.org/opendoors

[62] Salisbury, M.H., Paulsen, M.B. and Pascarella, E.T. (2010) To See the World or Stay at Home: Applying an Integrated Student Choice Model to Explore the Gender Gap in the Intent to Study Abroad. Research in Higher Education, 51, 615-640.

https://doi.org/10.1007/s11162-010-9171-6

[63] Gareis, E. (2012) Intercultural Friendship: Effects of Home and Host Region. Journal of International and Intercultural Communication, 5, 309-328. https://doi.org/10.1080/17513057.2012.691525

[64] Gareis, E. (2000) Intercultural Friendship: Five Case Studies of German Students in the USA. Journal of Intercultural Studies, 21, 67-91. https://doi.org/10.1080/07256860050000803

[65] Maeda, E. and Ritchie, D.L. (2003) The Concept of shinyuu in Japan: A Replication of and Comparison to Cole and Bradac's Study on U.S. Friendship. Journal of Social and Personal Relationships, 20, 579-598. https://doi.org/10.1177/02654075030205001

[66] Trice, A.G. (2007) Faculty Perspectives Regarding Graduate International Students' Isolation from Host National Students. International Education Journal, 8, 108-117.

[67] Davis, K.E. and Todd, M.J. (1982) Friendship and Love Relationships. In: Davis, K.E. and Mitchell, T.O., Eds., Advances in Descriptive Psychology, Vol. 2, 79-122, J.A.I. Press, Greenwich.

[68] Burke, M., Marlow, C. and Lento, T. (2010) Social Network Activity and Social Well-Being. Proceedings of the SIGCHI Conference on Human Factors in Computing Systems, Atlanta, 10-15 April 2010, 571-580. https://doi.org/10.1145/1753326.1753613

[69] Brandtzaeg, P.B. (2012) Social Networking Sites: Their Users and Social Implications-A Longitudinal Study. Journal of Computer-Mediated Communication, 17, 467-488. https://doi.org/10.1111/j.1083-6101.2012.01580.x

[70] Baym, N., Zhang, Y.B., Kunkel, A.D., Lin, M.-C. and Ledbetter, A. (2007) Relational Quality and Media Use in Interpersonal Relationships. New Media \& Society, 9, 735-752. https://doi.org/10.1177/1461444807080339

[71] McLuhan, M. and McLuhan, E. (1988) The Laws of Media: The New Science. University of Toronto Press, Toronto. 
[72] Rosen, D. and Suthers, D. (2011) Stigmergy and Collaboration: Tracing the Contingencies of Mediated Interaction. Proceedings of the 44 th Hawaii International Conference on System Sciences, Kauai, 4-7 January 2011, 1-10.

[73] Rosen, D., Roy Lafontaine, P. and Hendrickson, B. (2011) Couch Surfing: Belonging and Trust in a Globally Cooperative Online Social Network. New Media \& Society 13, 981-998. https://doi.org/10.1177/1461444810390341

[74] Rosen, D., Stefanone, M.A. and Lackaff, D. (2010) Online and Offline Social Networks: Investigating Culturally-Specific Behavior and Satisfaction. Proceedings of the 43rd Hawaii International Conference on System Sciences, Honolulu, 5-8 January 2010, 1-10.

[75] Shuter, R. (2011) Introduction: New Media across Cultures-Prospect and Promise. Journal of International and Intercultural Communication, 4, 241-245. https://doi.org/10.1080/17513057.2011.598041

[76] Yum, Y. and Hara, K. (2006) Computer-Mediated Relationship Development: A Cross-Cultural Comparison. Journal of Computer Mediated Communication, 11, 133-152. https://doi.org/10.1111/j.1083-6101.2006.tb00307.x

[77] Yildiz, S. (2009) Social Presence in the Web-Based Classroom: Implications for Intercultural Communication. Journal of Studies in International Education, 13, 4665. https://doi.org/10.1177/1028315308317654

[78] Park, N., Song, H. and Lee, K.M. (2014) Social Networking Sites and Other Media Use, Acculturation Stress, and Psychological Well-Being among East Asian College Students in the United States. Computers in Human Behavior, 36, 138-146. https://doi.org/10.1016/j.chb.2014.03.037

[79] Tran, L.T. and Pham, L. (2015) International Students in Transnational Mobility: Intercultural Connectedness with Domestic and International Peers, Institutions and the Wider Community. Compare: A Journal of Comparative and International Education, 46, 560-581.

[80] Leask, B. (2009) Using Formal and Informal Curricula to Improve Interactions between Home and International Students. Journal of Studies in International Education, 13, 205-221. https://doi.org/10.1177/1028315308329786

[81] Campbell, N. (2012) Promoting Intercultural Contact on Campus: A Project to Connect and Engage International and Host Students. Journal of Studies in International Education, 16, 205-227. https://doi.org/10.1177/1028315311403936

[82] O’Hara, K., Massimi, M., Harper, R., Rubens, S. and Morris, J. (2014) Everyday Dwelling with WhatsApp. Proceedings of the 17 th ACM Conference on Computer Supported Cooperative Work and Social Computing, Baltimore, 15-19 February 2014, 1131-1143. https://doi.org/10.1145/2531602.2531679

[83] WhatsApp (2016) One Billion. https://blog.whatsapp.com/ 


\section{Appendix}

\section{Interview Reference List}

\begin{tabular}{|c|c|c|c|c|c|}
\hline Ref. & Country & Age & Gender & University & Language \\
\hline 1 & USA & 21 & Female & Private & Spanish \\
\hline 2 & Germany & 21 & Female & Private & Spanish \\
\hline 3 & Colombia & 21 & Male & Private & Spanish \\
\hline 4 & Brazil & 22 & Male & Private & Spanish \\
\hline 5 & Germany & 23 & Female & Private & Spanish \\
\hline 6 & USA & 21 & Female & Private & Spanish \\
\hline 7 & Finland & 23 & Female & Private & English \\
\hline 8 & Germany & 25 & Male & Private & Spanish \\
\hline 9 & Colombia & 20 & Female & Private & Spanish \\
\hline 10 & Switzerland & 26 & Male & Private & Spanish \\
\hline 11 & Spain & 24 & Male & Private & Spanish \\
\hline 12 & USA & 20 & Female & Private & Spanish \\
\hline 13 & USA & 20 & Female & Private & Spanish \\
\hline 14 & Canada, Quebec & 21 & Female & Private & Spanish \\
\hline 15 & Austria & 23 & Male & Private & Spanish \\
\hline 16 & Czech Republic & 22 & Female & Private & Spanish \\
\hline 17 & USA & 20 & Female & US Program & Spanish \\
\hline 18 & USA & 20 & Female & US Program & Spanish \\
\hline 19 & USA & 20 & Male & US Program & Spanish \\
\hline 20 & Mexico & 25 & Female & Private & Spanish \\
\hline 21 & France & 22 & Female & Private & Spanish \\
\hline 22 & Spain & 21 & Female & Private & Spanish \\
\hline 23 & Spain & 22 & Female & Private & Spanish \\
\hline 24 & France & 23 & Male & Public & Spanish \\
\hline 25 & USA & 20 & Male & US Program & English \\
\hline 26 & USA & 20 & Female & US Program & English \\
\hline 27 & USA & 19 & Male & US Program & English \\
\hline 28 & USA & 20 & Female & US Program & Spanish \\
\hline 29 & USA & 21 & Male & US Program & Spanish \\
\hline 30 & USA & 21 & Female & US Program & English \\
\hline 31 & USA & 21 & Male & US Program & English \\
\hline 32 & Norway & 25 & Female & Public & Spanish \\
\hline 33 & Germany & 24 & Female & Public & Spanish \\
\hline 34 & Brazil & 32 & Female & Public & Spanish \\
\hline
\end{tabular}


Submit or recommend next manuscript to SCIRP and we will provide best service for you:

Accepting pre-submission inquiries through Email, Facebook, LinkedIn, Twitter, etc. A wide selection of journals (inclusive of 9 subjects, more than 200 journals)

Providing 24-hour high-quality service

User-friendly online submission system

Fair and swift peer-review system

Efficient typesetting and proofreading procedure

Display of the result of downloads and visits, as well as the number of cited articles Maximum dissemination of your research work

Submit your manuscript at: http://papersubmission.scirp.org/

Or contact $\underline{\text { sn@scirp.org }}$ 